\title{
Proximity of the middle meningeal artery and maxillary artery to the mandibular head and mandibular neck as revealed by three-dimensional time-of-flight magnetic resonance angiography
}

\author{
Daphne Schönegg ${ }^{1} \cdot$ Raphael Ferrari $^{1} \cdot$ Julian Ebner $^{1} \cdot$ Michael Blumer $^{1} \cdot$ Martin Lanzer $^{1} \cdot$ Thomas Gander $^{1}$
}

Received: 4 October 2020 / Accepted: 17 March 2021 / Published online: 23 May 2021

(c) The Author(s) 2021

\begin{abstract}
Purpose The close topographic relationship between vascular and osseous structures in the condylar and subcondylar region and marked variability in the arterial course has been revealed by both imaging and cadaveric studies. This study aimed to verify the previously published information in a large sample and to determine a safe surgical region.

Methods We analyzed the three-dimensional time-of-flight magnetic resonance angiography images of 300 individuals. Results The mean distance between the middle meningeal artery and the apex of the condyle or the most medial point of the condyle was $18.8 \mathrm{~mm}$ (range: $11.2-25.9 \mathrm{~mm}$ ) or $14.5 \mathrm{~mm}$ (range: $8.8-22.9 \mathrm{~mm}$ ) respectively. The course of the maxillary artery relative to the lateral pterygoid muscle was medial in $45.7 \%$ of cases and lateral in $54.3 \%$. An asymmetric course was evident in 66 patients (22\%). The mean distance between the maxillary artery and condylar process at the deepest point of the mandibular notch was $6.2 \mathrm{~mm}$ in sides exhibiting a medial course (range: $3.7-9.8 \mathrm{~mm}$ ) and $6.6 \mathrm{~mm}$ in sides exhibiting a lateral course (range: $3.9-10.4 \mathrm{~mm}$ ). The distances were significantly influenced by age, gender, and the course of the maxillary artery.

Conclusion Our study emphasizes the marked inter- and intra-individual variability of the maxillary and middle meningeal arterial courses. We confirmed the proximity of the arteries to the condylar process. Extensive surgical experience and thorough preparation for each individual case are essential to prevent iatrogenic vascular injury.
\end{abstract}

Keywords Maxillary artery $\cdot$ Middle meningeal artery $\cdot$ Mandibular condylar process $\cdot$ Topographic relationship

\section{Introduction}

The mandibular condylar process is a common surgical site after trauma and when reconstruction is required [1-6]. Surgeons are well-aware that the arteries supplying the temporomandibular joint (TMJ) run close to the facial bones, particularly to the mandibular condylar process. The limited visibility and accessibility associated with minimally invasive and endoscopic procedures in narrow anatomical regions are associated with a risk of iatrogenic vascular injury, which leads to bleeding that is difficult to control and potentially life-threatening.

Thomas Gander

Thomas.Gander@usz.ch

1 Department of Oral and Maxillofacial Surgery, University Hospital of Zürich, Frauenklinikstrasse 24, 8091 Zürich, Switzerland
Several imaging studies have described the close relationships between the maxillary and middle meningeal arteries and osseous structures [7-12]. However, the minimal distances between these structures remain difficult to predict for an individual patient; at present, it is not possible to generally delimit a safe surgical region. This is attributable principally to high inter- and intra-individual variability in the arterial course, which may reflect the complexity of embryological development [13-15]. Two main subtypes of maxillary arterial courses have been described based on their relationship with the lateral pterygoid muscle: a lateral or superficial type and a medial or deep type. The course is thought to be partly dependent on ethnicity and gender [16-18].

Here, we measured the distances between the maxillary and middle meningeal arteries and osseous landmarks, as revealed by three-dimensional time-of-flight magnetic resonance angiography (3D-TOF-MRA). This imaging technique is well suited to visualize vascular structures, especially in 
neuroradiological assessments. Due to its standard use in stroke diagnostics, a large number of data sets are easily available for further analysis. Compared to other imaging modalities such as contrast-enhanced computed tomography, 3D-TOF-MRA is characterized by good spatial resolution, contrast, and ease of use. We aimed to verify the previously published information in a large sample and to define a safe surgical region. A tabular summary of study results from the past decade complements this study.

\section{Materials and Methods}

A total of 300 individuals, equally distributed by gender (150 women, 150 men), who had undergone 3D-TOF-MRA as part of the routine diagnostic workup of the Swiss Stroke Registry between January 2017 and December 2018 in the Department of Neurology, University Hospital of Zürich, were included in this study.

Data were acquired using either an Ingenia (Philips, Amsterdam, Netherlands) or Magnetom (Siemens, Munich, Germany) $3 \mathrm{~T}$ magnetic resonance imaging (MRI) scanner, with the following settings: TR, $20 \mathrm{~ms}$; TE, $3.43 \mathrm{~ms}$; flip angle, $20^{\circ}$; slice thickness, $0.6 \mathrm{~mm}$; and acquisition matrix, $320 \times 238$.

The inclusion criteria were age $\geq 20$ years at the time of imaging, diagnosis of a transient ischemic attack (TIA) or TIA mimic, and consent (i.e., no documented refusal) to the further use of data. The exclusion criteria were osseous changes (caused by prior facial fracture, TMJ surgery, severe degenerative TMJ disease, a tumor, or an anatomical variant such as a bifid condyle) and any vascular pathology (prior carotid dissection, severe arteriosclerotic disease, carotid stenosis, cerebrovascular bypass surgery, or stroke). Patients with poor-quality images (usually because of movement artifacts) were also excluded.

Data on age and gender were extracted from patient charts. The 3D-TOF-MRA scans were collected from our picture archiving and communication system (PACS), imported into iPlan 3.0.5 ENT software (Brainlab, Munich, Germany), and aligned with predefined planes (the Frankfurt horizontal plane, the coronal plane connecting the outer acoustic meatus, and the median sagittal plane along the cerebral falx).

The courses of the right and left maxillary arteries were classified as either medial (deep) or lateral (superficial) by reference to the lateral pterygoid muscle, as shown on axial images (Fig. 1). The distance between the most apical point of the condyle and the middle meningeal artery was measured in the axial plane using iPlan. For this, the most apical point of the mandibular condyle was identified in the coronal and sagittal planes and marked using the iPlan "reference point" tool. Each axial view was automatically re-centered on the reference point and the center of the middle meningeal artery was then marked (Fig. 2).

A similar technique was used to measure the distance between the most medial point of the mandibular condyle and the middle meningeal artery. The most medial point of the condyle was identified in the coronal and axial planes. The distance between that point and the center of the middle meningeal artery was then measured on the automatically re-centered axial image (Fig. 3). To measure the distance between the maxillary artery and the condylar process, the deepest point of the mandibular notch was identified and marked in the sagittal plane. The coronal plane was re-centered to run through this reference
Fig. 1 Asymmetric course of the maxillary artery running medial to the lateral pterygoid muscle on the right and lateral to the lateral pterygoid muscle on the left side in the axial plane

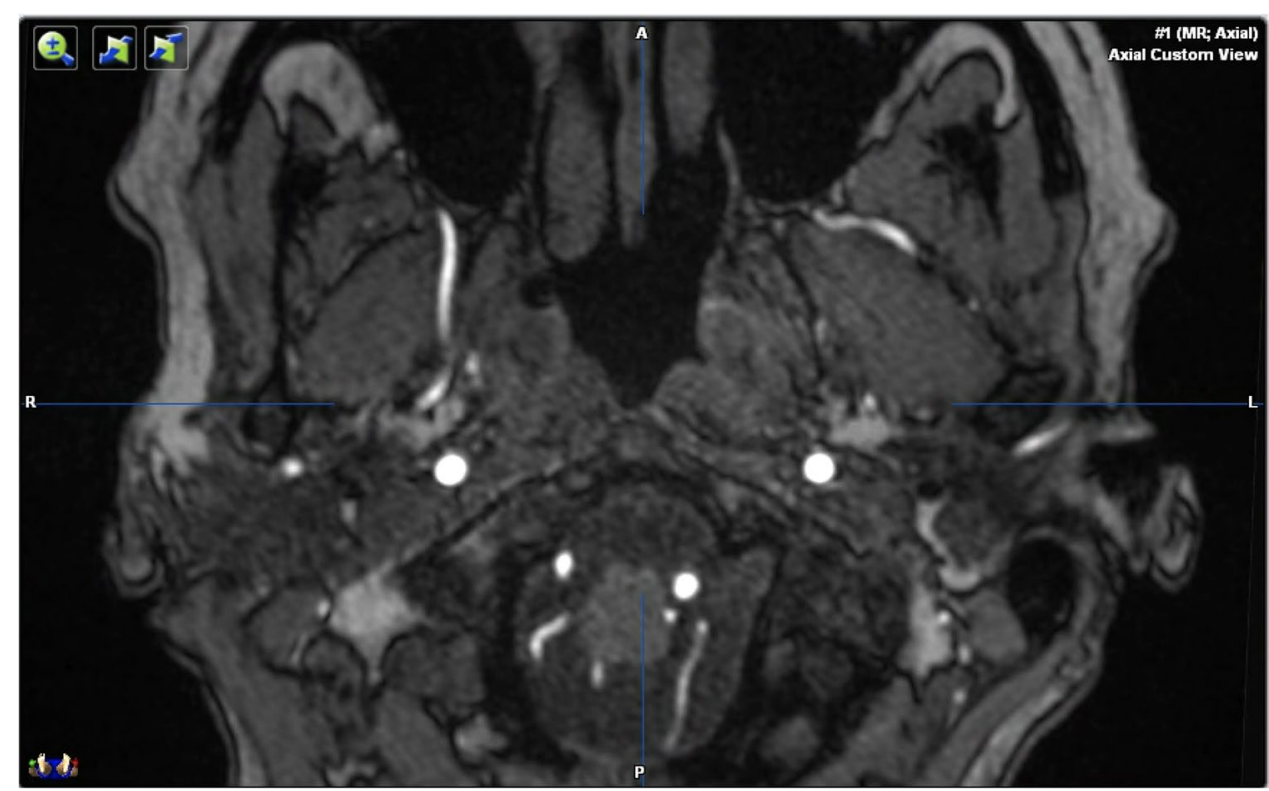


Fig. 2 Measurement of the distance between the most apical point of the condyle and the middle meningeal artery in the axial plane

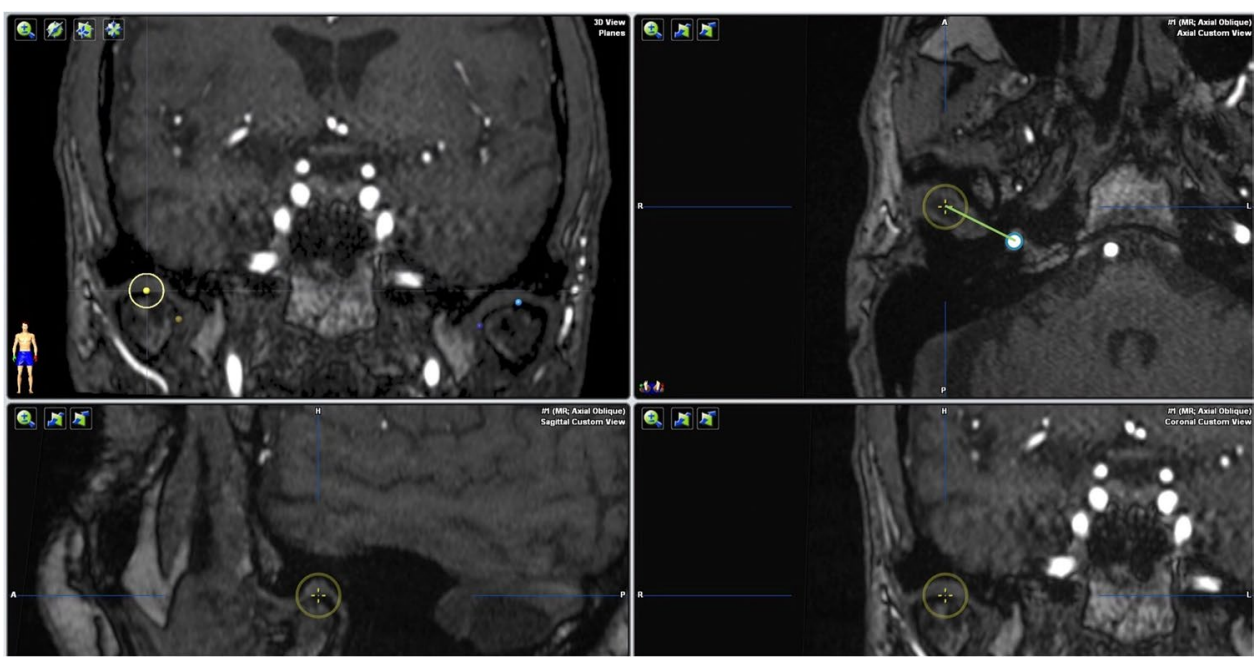

point, and the most lateral aspect of the maxillary artery was marked. The distance to the outer cortical bone of the condylar process was then measured on a horizontal line parallel to the reference line generated during image alignment (Fig. 4).

All measurements were made on both sides by the same investigator. Statistical analyses were performed using SPSS software (ver. 26.0; IBM Corp., Armonk, NY, USA) and included $t$-tests and Pearson correlation analysis. A $p$-value $\leq 0.05$ was considered to indicate statistical significance.

Ethical approval was obtained from the responsible Ethics committee (KEK Zürich; approval no.: 2018-02337). This study thus fulfills the criteria of the Declaration of Helsinki.

\section{Results}

We included 300 patients (150 women, 150 men) with a mean age of 66.1 years (median age, 70.4 years; range: 21.3-94.1 years). The mean age did not differ significantly between the sexes $(p=0.311)$. The course of the maxillary artery relative to the lateral pterygoid muscle was medial on 274 sides (45.7\%) and lateral on 326 sides (54.3\%). An asymmetric course was evident in 66 individuals $(22 \% ; 29$ women and $37 \mathrm{men}$ ). In 39 of these patients, the right maxillary artery ran medially to the lateral pterygoid muscle.

The mean distance between the most apical point of the condyle and the middle meningeal artery was $18.8 \mathrm{~mm}$ (median distance, $18.7 \mathrm{~mm}$; range: $11.2-25.9 \mathrm{~mm}$ ). The mean distance between the most medial point of the condyle and the middle meningeal artery was $14.5 \mathrm{~mm}$ (median distance, $14.4 \mathrm{~mm}$; range: $8.8-22.9 \mathrm{~mm}$ ). The mean distance between the maxillary artery and outer cortex of the mandibular condyle was $6.4 \mathrm{~mm}$ (median distance, $6.2 \mathrm{~mm}$; range: $3.7-10.4 \mathrm{~mm}$ );
Fig. 3 Measurement of the distance between the most medial point of the mandibular condyle and the middle meningeal artery in the axial plane

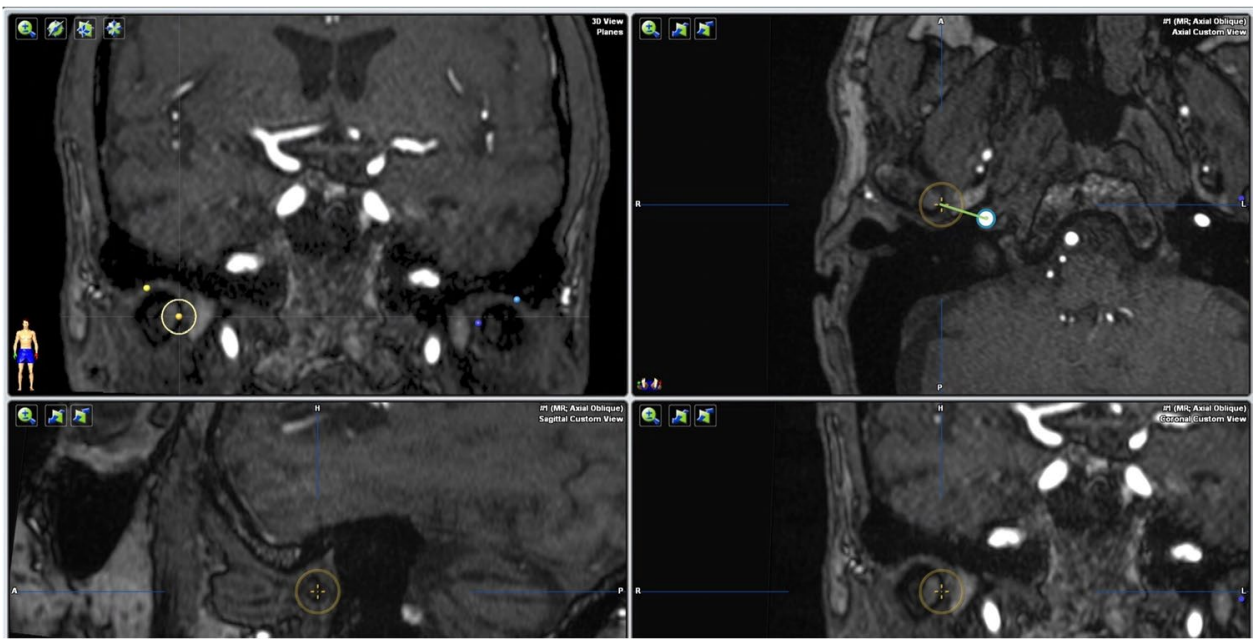


Fig. 4 Measurement of the distance between the maxillary artery and the condylar process in the coronal plane

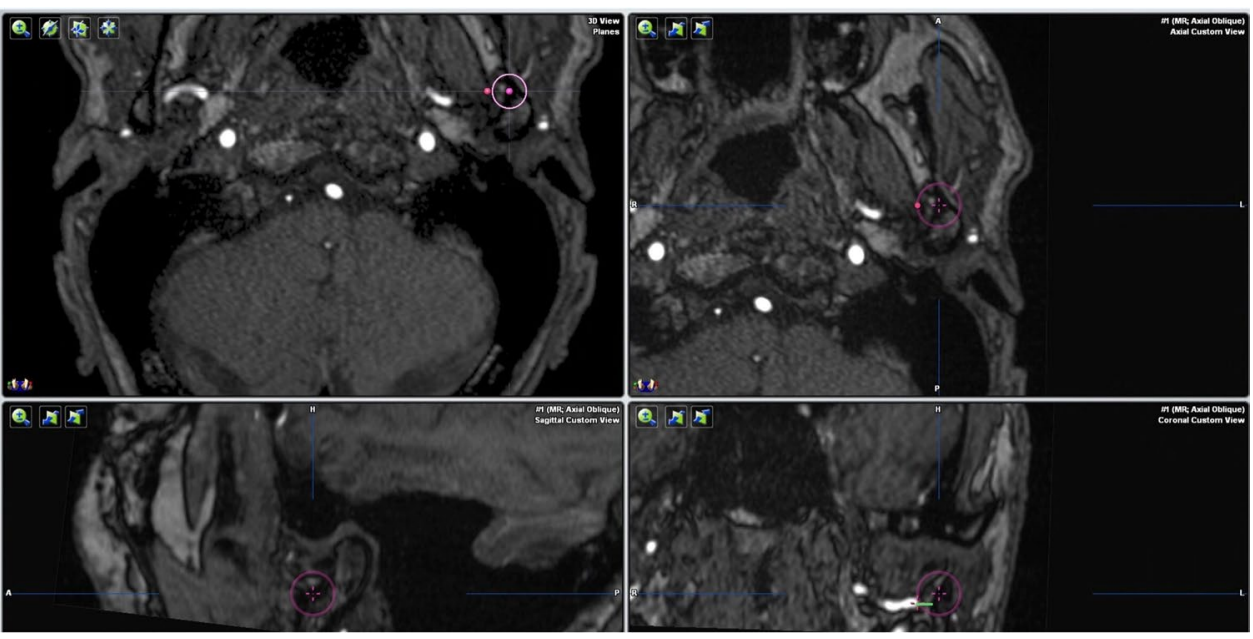

the distance differed significantly between sides with medial and lateral courses relative to the lateral pterygoid muscle $(p=0.000)$. The details are shown in Table 1. All three distances were significantly shorter in women. The distance between the most medial point of the condyle and the middle meningeal artery was significantly smaller on the left than on the right side $(p=0.042)$.
Pearson correlation analysis revealed a significant linear correlation between measurements on the left and right sides for all three distances; the correlation coefficients were 0.635 for the maxillary arterial measurements, and 0.772 and 0.808 , respectively, for measurements involving the most apical and most medial condylar aspects (all $p=0.000$ ). The mean distances between the middle meningeal artery and the most apical and most medial aspects

Table 1 Subgroup analysis of the mean distances between osseous landmarks and arteries

\begin{tabular}{|c|c|c|c|c|}
\hline Distance & Subgroup & Mean $(\mathrm{mm})$ & Median (mm) & $p$-value \\
\hline \multirow[t]{7}{*}{ From the apex of the condyle to the middle meningeal artery } & & 18.8 & 18.7 & \\
\hline & Right side & 18.9 & 19.1 & 0.093 \\
\hline & Left side & 18.6 & 18.3 & \\
\hline & Medial type & 18.8 & 18.8 & 0.626 \\
\hline & Lateral type & 18.7 & 18.6 & \\
\hline & Men & 19.5 & 19.7 & $0.000 *$ \\
\hline & Women & 18.1 & 18.1 & \\
\hline \multirow{7}{*}{$\begin{array}{l}\text { From the most medial point of the condyle to the middle meningeal } \\
\text { artery }\end{array}$} & & 14.5 & 14.4 & \\
\hline & Right side & 14.7 & 14.6 & $0.042 *$ \\
\hline & Left side & 14.4 & 14.2 & \\
\hline & Medial type & 14.6 & 14.4 & 0.982 \\
\hline & Lateral type & 14.5 & 14.4 & \\
\hline & Men & 14.8 & 14.6 & $0.004 *$ \\
\hline & Women & 14.3 & 14.1 & \\
\hline \multirow[t]{7}{*}{ From the condylar process to the maxillary artery } & & 6.4 & 6.2 & \\
\hline & Right side & 6.4 & 6.2 & 0.956 \\
\hline & Left side & 6.4 & 6.4 & \\
\hline & Medial type & 6.2 & 5.9 & $0.000 *$ \\
\hline & Lateral type & 6.6 & 6.6 & \\
\hline & Men & 6.6 & 6.5 & $0.000^{*}$ \\
\hline & Women & 6.2 & 6.0 & \\
\hline
\end{tabular}

*Significant difference at $p \leq 0.05$ 
of the condylar head were significantly correlated $(0.669 ; p=0.000)$. Age at the time of imaging was significantly correlated with the distances between the middle meningeal artery and the most apical and most medial condylar points $(0.249$ and 0.361 ; both $p=0.000)$, respectively.

\section{Discussion}

By using the Swiss Stroke Registry, we could include more patients in this study than in previous studies and achieve an equal sex distribution. We applied strict inclusion and exclusion criteria to minimize confounding. The minimum age of the patients was 20 years, to minimize any effect of residual mandibular growth. We lacked data on the extent of mouth-opening during MRA [7] and occlusion type $[19,20]$, both factors that can influence the position of the mandible in relation to the skull base. Our patients were older than those of previous studies (mean age, 66 years). This may be relevant in that degenerative TMJ disease or tooth loss, which affects occlusion and condylar morphology, is more common in the elderly [21-23].

Measurements were made on 3D-TOF-MRA images, which reveal arteries and bones at high spatial resolution, with a good signal-to-noise ratio and possibly higher accuracy due to the capture of dynamic flows. iPlan ENT software allows for automatic alignment, re-centering, and measurement of distances, thus enabling reproducible, reliable, and rapid analysis.

The maxillary and middle meningeal arteries are especially prone to iatrogenic injury during osteotomy, fragment repositioning, screw insertion, or surgical dissection near the articular eminence (prior to insertion of a TMJ prosthesis), especially in patients with TMJ ankylosis [24-30]. The reference points selected for our new measurement technique are chosen to correspond to landmarks that are easily identifiable intraoperatively. They can thus serve as a guide structure during surgery and facilitate surgeon orientation when avoiding proximity to the vessels.
Table 3 Literature review: medial and lateral courses of the maxillary artery relative to the lateral pterygoid muscle

\begin{tabular}{lllll}
\hline $\begin{array}{l}\text { First author, } \\
\text { year }\end{array}$ & $\begin{array}{l}\text { Number of } \\
\text { sides }\end{array}$ & Country & $\begin{array}{l}\text { Lateral } \\
\text { course }\end{array}$ & Medial course \\
\hline $\begin{array}{c}\text { Isolan, 2007 } \\
\text { [38] }\end{array}$ & 16 & USA & $100 \%$ & - \\
$\begin{array}{c}\text { Balcioglu, } \\
\text { 2010 [25] }\end{array}$ & 34 & Turkey & $100 \%$ & - \\
$\begin{array}{c}\text { Joo, } \\
\text { 2013 [39] }\end{array}$ & 20 & Korea & $80 \%$ & $20 \%$ \\
$\begin{array}{c}\text { Alvernia, } \\
2017[42]\end{array}$ & 20 & USA & $47.5 \%$ & $52.5 \%$ \\
$\begin{array}{c}\text { Polev, } \\
2019[40]\end{array}$ & 12 & Russia & $83.3 \%$ & $16.7 \%$ \\
\hline
\end{tabular}

The shape of the condylar process is variable and is influenced by several factors including age and gender [31]. Thus, we used the most apical and medial condylar points as references. Both points are clearly identifiable regardless of condylar shape and volume. The center of the middle meningeal artery was also a reference point, such that variation in vessel diameter $[12,32,33]$ and branching pattern [34-36] were not factors. The distance between the maxillary artery and condylar process was measured in the plane running through the deepest point of the mandibular notch, because that plane is easy to identify. We measured the distance from the outer cortex of the condylar process to the most lateral point of the maxillary artery, to balance the variation in bone thickness against the tortuosity of the artery and thus ensure consistent cuts.

The course of the maxillary artery relative to the lateral pterygoid muscle has been examined in several studies (Table 2). Of our patients, 22\% exhibited an asymmetric course, in agreement with the study of Gulses et al. [17], in which $21 \%$ of 209 patients showed an asymmetric course, but far higher than in studies with smaller numbers of cases (see Table 2). Wang et al. [18] comprehensively summarized the prevalence rates of lateral and medial courses reported by various studies. We found five additional relevant publications (Table 3). Several authors reported that the lateral course was more common in Asian and Black populations. The Swiss Stroke Registry does not document ethnicity. We
Table 2 Literature review: prevalence of symmetric and asymmetric courses of the maxillary artery relative to the lateral pterygoid muscle

\begin{tabular}{lll}
\hline & Symmetric (number of patients) & Asymmetric (number of patients, \% asymmetric) \\
\hline First author, year & Balcioglu, 2010 [25] (17) & Alvernia, 2017 (1/20=5\%) [42] \\
& Hussain, 2008 [37] (44) & Arimoto, 2015 $(1 / 19=5.3 \%)[7]$ \\
& Isolan, 2007 [38] (8) & Dennison, 2009 $(2 / 53=3.8 \%)[43]$ \\
& Joo, 2013 [39] (10) & Gulses, 2012 (44/209=21\%) [17] \\
& Polev, 2019 [40] (6) & Hwang, 2014 (12/100=12\%) [10] \\
& Uysal, 2011 [41] (7) & Maeda, 2012 (n.a.) [44] \\
& & Orbay, 2007 $(1 / 8=12.5 \%)[28]$ \\
& Otake, 2011 $(1 / 14=7.1 \%)[45]$ \\
\hline
\end{tabular}


Table 4 Literature review: distances between osseous landmarks and the maxillary artery

\begin{tabular}{|c|c|c|c|}
\hline First author, year & $\begin{array}{l}\text { Number } \\
\text { of sides }\end{array}$ & Measurement & Distance (mm) \\
\hline $\begin{array}{l}\text { Nastro Siniscalchi, } \\
2016[47]\end{array}$ & n.a & From the neck of the condyle to the maxillary artery & 6.8 \\
\hline Arimoto, 2015 [7] & 38 & $\begin{array}{l}\text { From the mandibular notch to the maxillary artery (measured on MRI scans obtained } \\
\text { with the mouth open and closed) }\end{array}$ & $\begin{array}{l}\text { Open: } 1.8 \pm 0.5 \\
\text { Closed: } 1.5 \pm 0.5\end{array}$ \\
\hline Hwang, 2014 [10] & 200 & $\begin{array}{l}\text { From the mandibular notch to the maxillary artery (measured on computer tomography } \\
\text { scans) }\end{array}$ & $\begin{array}{l}\text { Lateral: } 3.6 \pm 1.0 \\
\text { Medial: } 16.3 \pm 3.7\end{array}$ \\
\hline Balcioglu, 2010 [25] & 34 & $\begin{array}{l}\text { From the mandibular notch to the maxillary artery (cadaver measurements) } \\
\text { From the medial cortex to the maxillary artery (cadaver measurements) }\end{array}$ & $\begin{array}{l}2.94 \pm 0.52 \\
5.38 \pm 2.47\end{array}$ \\
\hline Orbay, 2007 [28] & 16 & From the mandibular notch to the maxillary artery (cadaver measurements) & 5.1 \\
\hline
\end{tabular}

noted a medial course in $45.7 \%$ of sides, comparable to the proportion reported in other European studies.

We found that the distances between the middle meningeal artery and the most apical and most medial points of the condyle process were highly variable, ranging from 8.8 to $22.9 \mathrm{~mm}$ and 11.2 to $25.9 \mathrm{~mm}$, respectively. These differences of around $10 \mathrm{~mm}$ in a narrow anatomical region underline the significant variation, and thus the importance of thorough preoperative preparation.

The course of the maxillary artery is known to be variable and tortuous [10, 14, 46]. Several authors have measured the distances between the maxillary artery and bony reference points. Four studies used methods similar to ours (Table 4). Compared to those studies, our distances were significantly shorter for sides exhibiting a medial maxillary arterial course. The differences are probably attributable to the use of different imaging modalities and alignment methods, and to differences in reference points, measurement techniques, and patient characteristics.

The distance between the mandibular condyle and the middle meningeal artery increases significantly with age. This may be attributable to degeneration (condylar flattening) or relaxation of the masticatory muscles, which increases the distance between the skull base and mandible. All three distances were significantly greater in men than women, in accordance with other studies [43, 48-50]. We found that the distance between the most medial point of the condyle and the middle meningeal artery differed significantly between the right and left sides, perhaps attributable to the combined effects of variation in the arterial course and condylar shape.

\section{Conclusion}

The courses of the middle meningeal and maxillary arteries are influenced by age, gender, and ethnicity, and are highly variable and tortuous in all three dimensions. Prediction of individual courses remains difficult. Identification of patients at risk for critical vessel-bone relationships is a first step towards safer surgery. Female gender, a medial course of the maxillary artery relative to the lateral pterygoid muscle, and small cephalometric measurements were risk factors for the proximity of the arteries to the facial bones. A detailed classification of the vascular course, consideration of occlusion type, and analysis of condylar shape would facilitate the interpretation of images. A safe surgical zone around the mandibular condylar process cannot be generally defined; instead, it should be emphasized that the arteries and condyle may be very close, i.e., separated by a distance as small as $3.7 \mathrm{~mm}$. Surgeons must consider the marked inter- and intra-individual variation, and the close relationships between osseous and vascular structures. If an aberrant vascular or bony anatomy is suspected, preoperative visualization can be helpful; this is especially important when planning TMJ prosthesis placement in a patient with ankylosis, because landmarks may be difficult to identify intraoperatively. 3D-TOF-MRA appears to be a suitable imaging modality in these cases. All available measures should be taken to reduce the risk of an intraoperative major vascular injury and bleeding. In addition to preoperative imaging, these include, for example, the use of an intraoperative navigation system, available intraoperative embolization by interventional radiology, or application of vessel loops to the external carotid artery.

Author contribution All authors have made substantial contributions to the final form of this manuscript, reviewed the final form and approved this version to be published.

Funding Open Access funding provided by Universität Zürich.

\section{Declarations}

Ethics approval Ethical approval was obtained from the responsible Ethics committee (KEK Zürich; approval no.: 2018-02337). This study thus fulfills the criteria of the Declaration of Helsinki. 
Consent to participate and consent for publication Informed consent was obtained from all individual participants included in this study.

Conflict of interest The authors declare no competing interests.

Open Access This article is licensed under a Creative Commons Attribution 4.0 International License, which permits use, sharing, adaptation, distribution and reproduction in any medium or format, as long as you give appropriate credit to the original author(s) and the source, provide a link to the Creative Commons licence, and indicate if changes were made. The images or other third party material in this article are included in the article's Creative Commons licence, unless indicated otherwise in a credit line to the material. If material is not included in the article's Creative Commons licence and your intended use is not permitted by statutory regulation or exceeds the permitted use, you will need to obtain permission directly from the copyright holder. To view a copy of this licence, visit http://creativecommons.org/licenses/by/4.0/.

\section{References}

1. Al-Moraissi EA, Ellis E (2015) Surgical treatment of adult mandibular condylar fractures provides better outcomes than closed treatment: a systematic review and meta-analysis. J Oral Maxillofac Surg 73(3):482-493

2. Berner T, Essig H, Schumann P, Blumer M, Lanzer M, Rücker M et al (2015) Closed versus open treatment of mandibular condylar process fractures: a meta-analysis of retrospective and prospective studies. J Craniomaxillofac Surg 43(8):1404-1408

3. Blumer M, Guggenbühl T, Wagner MEH, Rostetter C, Rücker M, Gander T (2019) Outcome of surgically treated fractures of the condylar process by an endoscopic assisted transoral approach. J Oral Maxillofac Surg 77(1):133.e1-e9

4. Blumer M, Wagner ME, Rücker M, Lanzer M, Essig H, Gander $\mathrm{T}$ (2020) Radiologic analysis of surgically treated fractures of the condylar process by an endoscopic-assisted transoral approach. J Oral Maxillofac Surg 78(7):1151-1155

5. Hoffman D, Puig L (2015) Complications of TMJ surgery. Oral Maxillofac Surg Clin North Am 27(1):109-124

6. Toure G (2018) Arterial vascularization of the mandibular condyle and fractures of the condyle. Plast Reconstr Surg 141(5):718e-e725

7. Arimoto S, Hasegawa T, Okamoto N, Shioyasono A, Tateishi C, Akashi M et al (2015) Determining the location of the internal maxillary artery on ultrasonography and unenhanced magnetic resonance imaging before orthognathic surgery. Int J Oral Maxillofac Surg 44(8):977-983

8. Bendrihem R, Vacher C (2017) Radiologic anatomy of the maxillary artery in the pterygopalatine area applied to Le Fort 1 osteotomies. Surg Radiol Anat 39(1):23-27

9. Guo Y, Guo C (2014) Maxillary-fronto-temporal approach for removal of recurrent malignant infratemporal fossa tumors: Anatomical and clinical study. J Craniomaxillofac Surg 42(3):206-212

10. Hwang SH, Joo YH, Seo JH, Kang JM (2014) Proximity of the maxillary artery to the mandibular ramus: an anatomic study using three-dimensional reconstruction of computer tomography. Clin Anat 27(5):691-697

11. Lepić T, Lepić M, Mandić-Rajčević S (2019) Ultrasonographic assessment of the maxillary artery and middle meningeal artery in the infratemporal fossa. J Clin Ultrasound 47(7):405-411

12. Yağmurlu K, Kalani MYS, Martirosyan NL, Safavi-Abbasi S, Belykh E, Laarakker AS et al (2017) Maxillary artery to middle cerebral artery bypass: a novel technique for exposure of the maxillary artery. World Neurosurg 100:540-550

13. Cuccia AM, Caradonna C, Caradonna D, Anastasi G, Milardi D, Favaloro A et al (2013) The arterial blood supply of the temporomandibular joint: an anatomical study and clinical implications. Imaging Sci Dent 43(1):37-44

14. Tanoue S, Kiyosue H, Mori H, Hori Y, Okahara M, Sagara Y (2013) Maxillary artery: functional and imaging anatomy for safe and effective transcatheter treatment. Radiographics 33(7):e209-e224

15. Wysocki J, Reymond J, Krasucki K (2012) Vascularization of the mandibular condylar head with respect to intracapsular fractures of mandible. J Craniomaxillofac Surg 40(2):112-115

16. Aland RC, Shaw V (2016) Divided maxillary artery in relation to the lateral pterygoid muscle. Anat Sci Int 91(2):207-210

17. Gulses A, Oren C, Altug HA, Ilica T, Sencimen M (2012) Radiologic assessment of the relationship between the maxillary artery and the lateral pterygoid muscle. J Craniofac Surg 23(5):1465-1467

18. Wang L, Cai L, Lu S, Qian H, Lawton MT, Shi X (2018) The history and evolution of internal maxillary artery bypass. World Neurosurg 113:320-332

19. Ganugapanta VR, Ponnada SR, Gaddam KP, Perumalla K, Khan I, Mohammed NA (2017) Computed tomographic evaluation of condylar symmetry and condyle-fossa relationship of the temporomandibular joint in subjects with normal occlusion and malocclusion: a comparative study. J ClinDiagn Res 11(2):ZC29-ZC33

20. Hara S, Mitsugi M, Kanno T, Nomachi A, Kageyama I, Tatemoto Y (2014) Risk of maxillary artery injury during an intraoral vertical ramus osteotomy in Japanese patients is high-is it enough just to avoid damaging the inferior alveolar nerve? J Oral Maxillofac Surg 72(7):1373-1390

21. Huumonen S, Sipilä K, Haikola B, Tapio M, Söderholm AL, Remes-Lyly T et al (2010) Influence of edentulousness on gonial angle, ramus and condylar height. J Oral Rehabil 37(1):34-38

22. Sairam V, Potturi GR, Praveen B, Vikas G (2018) Assessment of effect of age, gender, and dentoalveolar changes on mandibular morphology: a digital panoramic study. Contemp Clin Dent 9(1):49-54

23. Yalcin ED, Ararat E (2019) Cone-beam computed tomography study of mandibular condylar morphology. J Craniofac Surg 30(8):2621-2624

24. Alderazi YJ, Shastri D, Wessel J, Mathew M, Kass-Hout T, Aziz SR et al (2017) Internal maxillary artery preoperative embolization using n-butyl cyanoacrylate and pushable coils for temporomandibular joint ankylosis surgery. World Neurosurg 101:254-258

25. Balcioglu HA, Kilic C, Varol A, Ozan H, Kocabiyik N, Yildirim M (2010) A Morphometric Study of the maxillary artery and lingula in relation to mandibular ramus osteotomies and TMJ surgery. Eur J Dent 4(2):166-170

26. Hossameldin RH, McCain JP, Dabus G (2017) Prophylactic embolisation of the internal maxillary artery in patients with ankylosis of the temporomandibular joint. Br J Oral Maxillofac Surg 55(6):584-588

27. Iwai T, Matsui Y, Omura S, Tohnai I (2013) Endoscopic hemostasis with an ultrasonically activated device for hemorrhage from a branch of the maxillary artery during endoscopically assisted reduction of condylar neck fracture. J Craniofac Surg 24(2):534-535

28. Orbay H, Kerem M, Unlü RE, Cömert A, Tüccar E, Şensöz O (2007) Maxillary artery: anatomical landmarks and relationship with the mandibular subcondyle. Plast ReconstrSurg 120(7):1865-70 
29. Pandyan DA, Siroraj P, Nandakumar, Narayanan CD (2014) Pseudoaneurysm of internal maxillary artery--an untold complication following distraction osteogenesis--a case report. J Oral Maxillofac Surg 72(3):605 e1-7

30. Walker CJ, MacLeod SP (2017) Anatomy and biomechanics of condylar fractures. Atlas Oral Maxillofac Surg Clin North Am 25(1):11-16

31. Saccucci M, Polimeni A, Festa F, Tecco S (2012) Do skeletal cephalometric characteristics correlate with condylar volume, surface and shape? A 3D analysis. Head Face Med 8:15

32. Kornieieva M, Hadidy A, Zhuravlova I (2015) Variability of the middle meningeal artery subject to the shape of skull. J Neurol Surg B Skull Base 76(6):451-458

33. Krayenbühl N, Isolan GR, Al-Mefty O (2008) The foramen spinosum: a landmark in middle fossa surgery. Neurosurg Rev 31(4):397-401 (discussion -2)

34. Cvetko E, Bosnjak R (2014) Unilateral absence of foramen spinosum with bilateral ophthalmic origin of the middle meningeal artery: case report and review of the literature. Folia Morphol (Warsz) 73(1):87-91

35. Ellwanger JH, Campos D (2013) Abnormality of the foramen spinosum due to a variation in the trajectory of the middle meningeal artery: a case report in human. J Neurol Surg Rep 74(2):73-76

36. Harthmann da Silva T, Ellwanger JH, Silva HT, Moraes D, Dotto AC, VieraVe A et al (2013) Morphometric analysis of the middle meningeal artery organization in humans-embryological considerations. J NeurolSurg B Skull Base 74(2):108-12

37. Hussain A, Binahmed A, Karim A, Sándor GK (2008) Relationship of the maxillary artery and lateral pterygoid muscle in a Caucasian sample. Oral Surg Oral Med Oral Pathol Oral Radiol Endod 105(1):32-36

38. Isolan GR, Rowe R, Al-Mefty O (2007) Microanatomy and surgical approaches to the infratemporal fossa: an anaglyphic three-dimensional stereoscopic printing study. Skull Base 17(5):285-302

39. Joo W, Funaki T, Yoshioka F, Rhoton AL (2013) Microsurgical anatomy of the infratemporal fossa. Clin Anat 26(4):455-469

40. Polev GA, Carrau RL, Golbin DA, Avdeeva KS, Grachev NS, Vorozhtsov IN et al (2019) Intraoral endoscopic ligation of maxillary artery in the infratemporal fossa. J Craniofac Surg 30(1):137-140
41. Uysal II, Büyükmumcu M, Dogan NU, Seker M, Ziylan T (2011) Clinical significance of maxillary artery and its branches: a cadaver study and review of the literature. Int J Morphol 29:1274-1281

42. Alvernia JE, Hidalgo J, Sindou MP, Washington C, Luzardo G, Perkins E et al (2017) The maxillary artery and its variants: an anatomical study with neurosurgical applications. Acta Neurochir (Wien) 159(4):655-664

43. Dennison J, Batra A, Herbison P (2009) The maxillary artery and the lateral pterygoid muscle: the New Zealand story. Oral Surg Oral Med Oral Pathol Oral Radiol Endod 108(5):e26-e29

44. Maeda S, Aizawa Y, Kumaki K, Kageyama I (2012) Variations in the course of the maxillary artery in Japanese adults. Anat Sci Int 87(4):187-194

45. Otake I, Kageyama I, Mataga I (2011) Clinical anatomy of the maxillary artery. Okajimas Folia Anat Jpn 87(4):155-164

46. Akiyama O, Güngör A, Middlebrooks EH, Kondo A, Arai H (2018) Microsurgical anatomy of the maxillary artery for extracranial-intracranial bypass in the pterygopalatine segment of the maxillary artery. Clin Anat 31(5):724-733

47. Nastro Siniscalchi E, Catalfamo L, Pitrone A, Papa R, Fam F, Lo Giudice G, et al (2016) Traumatic Pseudoaneurysm of the internal maxillary artery: a rare life-threatening hemorrhage as a complication of maxillofacial fractures. Case Rep Med 2016:9168429

48. Baur DA, Beushausen M, Leech B, Quereshy F, Fitzgerald N (2014) Anatomic study of the distance between the articular eminence and foramen spinosum and foramen spinosum and petrotympanic fissure. J Oral Maxillofac Surg 72(6):1125-1129

49. Safi AF, Kauke M, Grandoch A, Nickenig HJ, Zöller JE, Kreppel M (2018) Age-related volumetric changes in mandibular condyles. J Craniofac Surg 29(2):510-513

50. Vuksanovic-Bozaric A, Vukcevic B, Abramovic M, Vukcevic N, Popovic N, Radunovic M (2019) The pterygopalatine fossa: morphometric CT study with clinical implications. Surg Radiol Anat $41: 161$

Publisher's note Springer Nature remains neutral with regard to jurisdictional claims in published maps and institutional affiliations. 